\title{
RESEARCH
}

Open Access

\section{Social ecological factors associated with physical activity and screen time amongst mothers from disadvantaged neighbourhoods over three years}

\author{
Kylie A. Morris ${ }^{1 *} \mathbb{D}$, Lauren Arundell ${ }^{2}$, Verity Cleland ${ }^{2,3}$ and Megan Teychenne ${ }^{2}$
}

\begin{abstract}
Background: Mothers from socioeconomically disadvantaged neighbourhoods are at elevated risk of physical inactivity and high levels of screen time. Yet, little is known regarding the social ecological factors that are longitudinally associated with physical activity and screen time in this target group, and whether the age of their children impacts these relationships. This study aimed to longitudinally examine the social ecological factors associated with physical activity and screen time amongst mothers living in socioeconomically disadvantaged neighbourhoods, and whether these differed according to their child's age.

Methods: Data were from 895 mothers living in socioeconomically disadvantaged neighbourhoods (mean age 36.7 years) at baseline and three-year follow-up. Mothers self-reported weekly discretionary physical activity (leisure-time, LTPA; transport-related, TRPA) and screen time durations. Linear regression models assessed associations between five intrapersonal, three social and five physical environmental factors and LTPA, TRPA and screen time, adjusting for confounding factors, clustering by neighbourhood and baseline variables. Interaction analysis was conducted for age of children (younger and older children $(n=442)$ and mothers with older children (aged 5-12 years) only $(n=453)$.

Results: In adjusted models, all intrapersonal factors (self-efficacy, enjoyment, outcome expectations, behavioural intentions and behavioural skill), social support from friends, neighbourhood cohesion and number of televisions were longitudinally associated with LTPA amongst all mothers. Interaction models showed that findings were generally consistent across groups (i.e., those with both younger and older children compared to those with older children only), with three exceptions. Physical activity enjoyment and social support from family were associated with LTPA only among mothers with older children. Neighbourhood cohesion was associated with screen time only amongst mothers with both younger and older children. No associations were detected for TRPA.

(Continued on next page)
\end{abstract}

\footnotetext{
* Correspondence: k.morris@deakin.edu.au

'Geelong, Australia, School of Exercise and Nutrition Sciences, Deakin

University, Melbourne Burwood Campus, 221 Burwood Hwy, Burwood, VIC

3125, Australia

Full list of author information is available at the end of the article
}

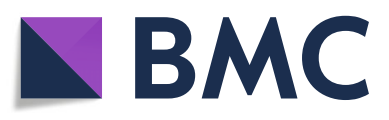

(- The Author(s). 2020 Open Access This article is licensed under a Creative Commons Attribution 4.0 International License, which permits use, sharing, adaptation, distribution and reproduction in any medium or format, as long as you give appropriate credit to the original author(s) and the source, provide a link to the Creative Commons licence, and indicate if changes were made. The images or other third party material in this article are included in the article's Creative Commons licence, unless indicated otherwise in a credit line to the material. If material is not included in the article's Creative Commons licence and your intended use is not permitted by statutory regulation or exceeds the permitted use, you will need to obtain permission directly from the copyright holder. To view a copy of this licence, visit http://creativecommons.org/licenses/by/4.0/. The Creative Commons Public Domain Dedication waiver (http://creativecommons.org/publicdomain/zero/1.0/) applies to the data made available in this article, unless otherwise stated in a credit line to the data. 


\begin{abstract}
(Continued from previous page)
Conclusion: Intrapersonal, social and physical environmental factors were longitudinally associated with mother's LTPA, whilst neighbourhood cohesion was longitudinally associated with screen time behaviours amongst mothers. Interventions aimed at increasing LTPA amongst mothers (particularly those from socioeconomically disadvantaged neighbourhoods) may need to target all domains of the social ecological model and may require some tailoring according to the age of children. Further work is needed to identify longitudinal associations with screen time and TRPA in this population group.
\end{abstract}

Keywords: Physical activity, Sedentary behaviour, Screen time, Mothers, Socioeconomic disadvantage

\section{Background}

Physical inactivity is the fourth leading risk factor for mortality globally, contributing annually to over three million preventable deaths [1]. Physical activity has been linked to reduced risk of physical [2] and mental [3] health conditions. Despite this, more than half the population in countries such as Australia, the US and the UK [4-6] do not meet current physical activity guidelines, with women less physically active than men [5, 7]. As women enter into motherhood, there is a decline in physical activity [8-11], where $85 \%$ of women have reported they were more active before having children [10]. Furthermore, first-time mothers were 1.8 times more likely to be inactive compared to women without children 4 years after motherhood [11]. This indicates that the negative changes in mother's health behaviours are still occurring many years after the birth of their child.

Engaging in high levels of sedentary behaviour (e.g., TV viewing, computer use, occupational sitting) has been linked to increased risk of physical [2] and mental health conditions $[3,12]$, independent of physical activity [13]. Yet women spend on average $39 \mathrm{~h}$ per week engaged in sedentary behaviour [4], with about half $(20 \mathrm{~h})$ of this time in television viewing [4]. Higher rates of sedentary behaviour have been seen in women (52\%), compared to men (42\%) [4], with increases in sedentary behaviour escalating during motherhood [11].

Internationally [6] certain sub-groups are at greater risk of physical inactivity and sedentary behaviours, including women (particularly mothers) and those living in socioeconomically disadvantaged neighbourhoods. Specifically, mothers from socioeconomically disadvantaged neighbourhoods participate 38 min per week less physical activity than mothers living in less disadvantaged neighbourhoods [11]. In order to inform targeted and effective intervention strategies it is important to understand factors that may influence these behaviours. The social ecological model [14] has been used in behavioural research to examine the factors that may influence physical activity and/or sedentary behaviours. This model recognises multiple levels of influence on behaviour, encompassing intrapersonal (motivation, selfefficacy, ability and goal setting), social (support from family/spouse and friends/work colleagues) and physical environmental (recreational facilities, personal safety and likeable neighbourhoods) constructs [14, 15].

Overall, little research has examined the longitudinal factors associated with mothers' physical activity and sedentary behaviour across the multiple levels of the social ecological model, nor have studies acknowledged that these longitudinal associations may differ between mothers with younger children and mothers with older children [16, 17]. Previous research has shown factors associated with mothers' physical activity levels are intrapersonal (e.g., time constraints [18-21], being tired or fatigued $[18,22]$ ), from the social environment (e.g., support from family, friends and work colleagues [20, 22], childcare access $[18,21,22])$ and from the physical environment (e.g., access to facilities [20, 23], cost of facilities [20, 24]). Regarding mothers' sedentary behaviours far fewer studies have examined these factors. However, amongst women generally, intrapersonal (e.g., leisure-time physical activity $[25,26]$, weight status $[25,27])$ and physical environmental factors (e.g., area of residence $[25,28]$ ) have been associated with sedentary behaviour. Few studies have examined associations between social factors and women's sedentary behaviour levels, highlighting a major gap in the research. Most existing studies are crosssectional $[18,23]$ meaning they are unable to determine the direction of relationships, and very few included mothers from socioeconomically disadvantaged neighbourhoods [26, 29].

Therefore, the aim of this study was to longitudinally examine the intrapersonal, social and physical environmental factors associated with engaging in physical activity and screen time amongst mothers (with children aged $0-$ 12 years) living in socioeconomically disadvantaged neighbourhoods. Additionally, this study examines whether any associations differ according to the age of the children.

\section{Methods}

Findings are reported according to STROBE guidelines [30]. Self-report data in 2007-08 and 2010-11 was collected, as part of a longitudinal study: the Resilience for Eating and Activity Despite Inequality [READI] study [9, 31]. The READI study was approved by the Deakin University Human 
Research Ethics Committee and all participants provided written consent. A detailed description of the study is provided elsewhere [31].

\section{Sample and data collection}

An area-level indicator of socioeconomic disadvantage (the Index of Relative Socio-economic Disadvantage [SEIF A]) determined by the population census that considers factors such as income, employment and education [32], was used to classify all Victorian neighbourhoods. Neighbourhoods in the bottom third were considered 'disadvantaged'. From this sample, women (aged 18-45 years) residing in 40 urban and 40 rural socioeconomically disadvantaged neighbourhoods were randomly selected to participate. The Australian Electoral Roll was used to randomly choose 150 women from each of the 80 neighbourhoods, with a total sampling pool of 11,940 women aged 18-45 years invited to participate. A total of 4938 completed surveys were completed (proportion of responses $=45 \%$ ). After applying eligibility criteria there were 4349 respondents at baseline (T1) (refer Fig. 1). A follow-up survey was sent 3 years after baseline (T2: 2010-11) to women who indicated they were happy to be re-contacted about future research $(n=3019)$. Completed T2 surveys were collected from 1912 respondents (63\% of eligible participants). Women were excluded from the current study if they did not have a child aged $\leq 12$ years living at home at baseline and did not have complete independent and outcome variable data at T1 and T2 $(n=895$ included; $n=1017$ excluded).

\section{Outcome variables \\ Physical activity}

Participants reported their frequency and duration of physical activity over the past week across four domains (occupation, transport, leisure, domestic) using the International Physical Activity Questionnaire - long form (IPAQ-L) [33]. A reliable (pooled $r=0.81$ ) and valid (mean $p=0.30$ ) tool for examining adult population levels of physical activity. For this study, only leisure-time and transport-related physical activity were investigated since these activities are typically discretional and are more likely to be targeted in physical activity interventions for mothers. For both the leisure-time and transport domains, time (frequency $\mathrm{x}$ duration) was summed to calculate the total weekly time spent (in minutes) being active within these domains. The data was truncated according to an established protocol [34].

\section{Screen time}

Participants reported time spent in screen time (i.e., combined computer and television use) over the past

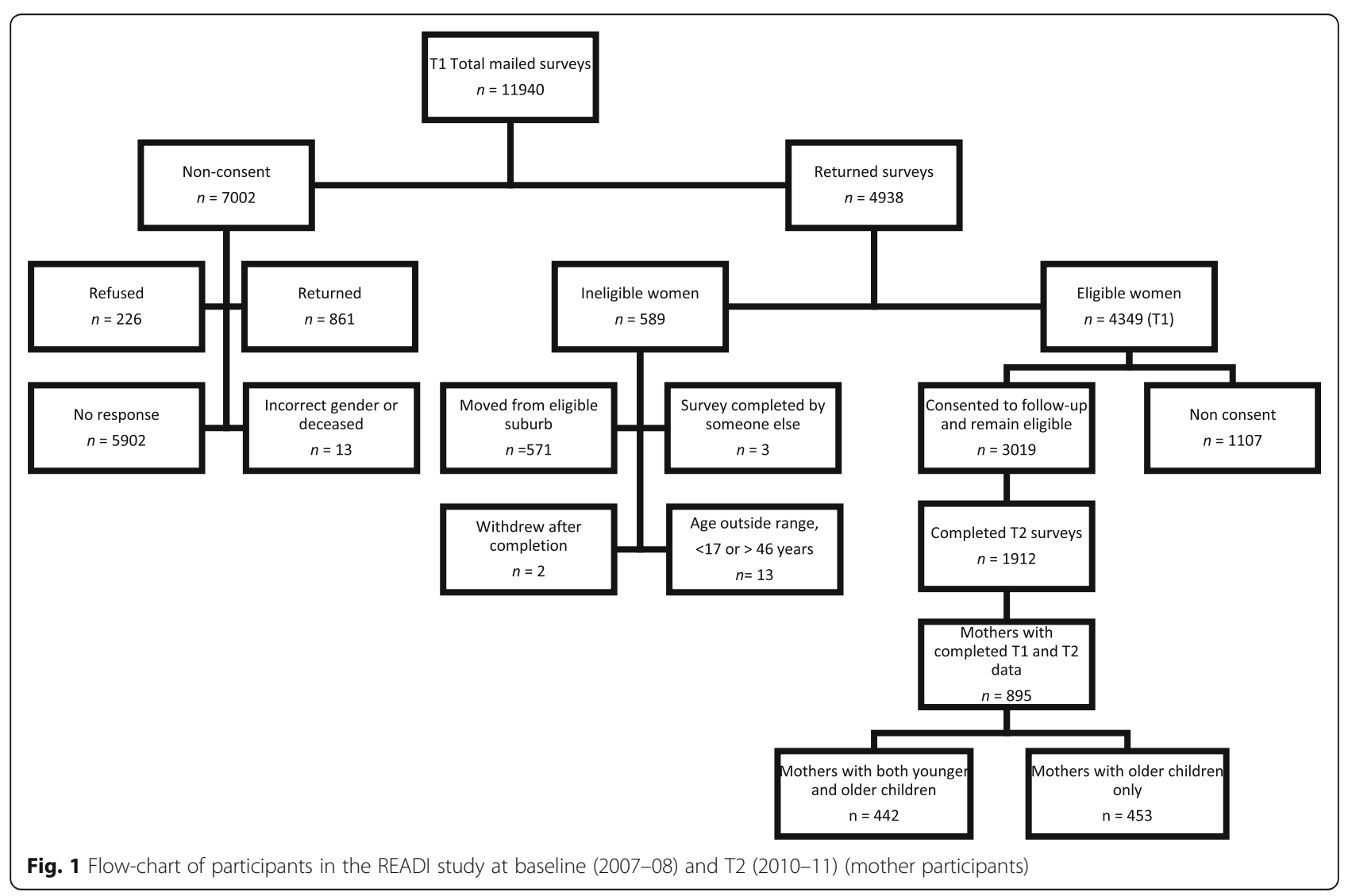


week. Valid and reliable measures (Intraclass Correlation Coefficients [ICC]) were used to record separately time spent sitting watching television (ICC $=0.82)$ and sitting using the computer $(\mathrm{ICC}=0.62)$ [35]. An ICC 0.40-0.75 represents a fair to good agreement and $>0.75$ represents excellent agreement [35]. Both television viewing and computer use duration were computed (sum of [weekday $\times 5]+[$ weekend day $\times 2]$ ). The data was truncated using an adapted protocol [34]. Weekly screen time' duration was calculated by adding the weekly duration for the variables 'television viewing' and 'computer use'.

\section{Independent variables}

Thirteen independent variables encompassing three constructs of the social ecological model (i.e., intrapersonal, social, physical environmental) were included in the analysis. These items were from previously developed studies and have been tested for reliability [36-42]. Details of these constructs and questions included are provided in Table 1. For variables with more than one item (e.g., neighbourhood walkability), items were summed to calculate a total score for that variable.

\section{Sociodemographic characteristics}

Participants reported their age, highest educational level (low $=<$ Year 12; medium $=$ Year 12, certificate/trade/diploma; high = tertiary), number and age of children living at home ( $<2$ years, $2-4$ years, $5-12$ years). Weight status (calculated as body mass index [BMI]) from reported height and weight data $(\mathrm{kg} / \mathrm{m} 2)$ using established methods [43] and categorised as: not overweight (BMI < $25 \mathrm{~kg} / \mathrm{m}^{2}$ ), overweight (BMI $25-29.9 \mathrm{~kg} / \mathrm{m}^{2}$ ) or obese $\left(\mathrm{BMI} \geq 30 \mathrm{~kg} / \mathrm{m}^{2}\right)$ [44]).

\section{Missing data}

Participants were excluded where they did not contain complete independent or outcome variables for the specific analyses of interest. Variables with missing baseline data included; age $(0.22 \%)$, education $(0.56 \%)$, household income (7.04\%), employment status (1.79\%), paid work status $(1.90 \%)$, marital status $(0.11 \%)$, BMI status $(4.47 \%)$, physical activity enjoyment (1.56\%), outcome expectations $(0.78 \%)$, self-efficacy $(0.34 \%)$, childcare $(0.11 \%)$, physical activity family support (0.34\%), physical activity friend support $(0.22 \%)$, screen time family support $(0.45 \%)$, screen time friend support (0.45\%), neighbourhood cohesion $(0.34 \%)$, aesthetics $(0.67 \%)$, safety $(0.22 \%)$, walkability $(0.78 \%)$, leisure time physical activity (3.02\%), transport related physical activity (3.02\%), screen time activity (7.93\%).

\section{Statistical analysis}

Data was analysed in Stata version 15. Descriptive statistics (mean and standard deviation for continuous data and frequencies and percent for categorical data) were used to explore the sociodemographic characteristics of the sample of mothers at baseline (Table 2). Medians and inter-quartile ranges were used to describe the behavioural characteristics of mothers at baseline and follow-up (Table 3) due to the non-normal distribution of the physical activity and sedentary behaviour data. To address the studies aims, crude (adjusted only for baseline outcome value and clustering by neighbourhood) and adjusted (adjusted for baseline outcome value, clustering by neighbourhood and potential confounders of age, education, number of children, weight status and number of paid hours worked) linear regression models were used. These models were used to examine the longitudinal association between the independent variables (intrapersonal, social and environmental factors) reported at T1 and the outcome variables (i.e., leisure-time physical activity, transport related physical activity or screen time) reported at T2. Confounders were selected based on being theoretically associated with both outcome and independent variables. Separate linear regression models were run for each of the outcome variables (i.e., leisure-time activity, transport-related activity, and screen time) against each of the thirteen independent variables.

Secondly, to detect an interaction between mothers according to the age of the child at baseline, mothers were categorised into two groups; mothers with both younger and older children (includes those with a least one child aged 0 5 years) and mothers with older children only (includes those only with children aged 5-12 years). Linear regression models were used to examine associations between the independent and outcome variables of the two mothers' groups. This involved adding an interaction term (age group of child*outcome) into the models. Where there was a significant interaction $(p<0.05)$, further regression models were stratified to examine relationships between the outcome and independent variables separately for each mothers group (those with both younger and older children and mothers with only older children only). The residual and predicted values met the assumptions of homoscedasticity. The distributions of each outcome variable were tested for normality and subsequently transformed to be as close as possible to a normal distribution using a square root transformation. Collinearity was assessed by examining the variance inflation factor [VIF] values and these were acceptably low $(<2)$.

\section{Results}

\section{Sociodemographic characteristics of the sample}

Sociodemographic characteristics of the sample consisted of 893 mothers (mothers $n=442$ with both younger and older children and mothers $n=453$ with older children only) and are presented in Table 2.

\section{Physical activity and screen time}

Mothers reported a median of $1.7 \mathrm{~h}$ of leisure-time physical activity per week at baseline and $2 \mathrm{~h}$ at follow-up 
Table 1 Survey items used to examine intrapersonal, social and physical environmental factors in the READI study

\begin{tabular}{|c|c|c|c|c|}
\hline Variable & Likert scale/response options & $\begin{array}{l}\text { Internal } \\
\text { reliability } \\
\left(\text { (a) }^{\mathrm{a}}\right.\end{array}$ & $\begin{array}{l}\text { Data } \\
\text { management }\end{array}$ & Questions used to assess variable \\
\hline \multicolumn{5}{|l|}{ Intrapersonal factors } \\
\hline $\begin{array}{l}\text { Behavioural skills } \\
{[36]}\end{array}$ & $\begin{array}{l}\text { 4-point: } 1 \text { (never), } 2 \text { (once or } \\
\text { twice), } 3 \text { (weekly), } 4 \text { (more than } \\
\text { once/week) }\end{array}$ & 0.83 & Sum 2 items & $\begin{array}{l}\text { How many times in the past month did you: 'Set a goal for how } \\
\text { much physical activity you would like to do?', 'Plan particular } \\
\text { days on which you would do physical activity?' }\end{array}$ \\
\hline $\begin{array}{l}\text { Behavioural } \\
\text { intentions [36] }\end{array}$ & $\begin{array}{l}\text { 7-point: } 1 \text { (very unlikely), } \\
7 \text { (very likely) }\end{array}$ & N/A & dichotomise & $\begin{array}{l}\text { Assuming that you tried to do physical activity over the next } 2 \\
\text { weeks, how likely or unlikely is it that you would actually stick to } \\
\text { this? }\end{array}$ \\
\hline $\begin{array}{l}\text { Outcome } \\
\text { expectancies [38] }\end{array}$ & $\begin{array}{l}\text { 4-point: } 1 \text { (no reason at all), } \\
4 \text { (very important reason) }\end{array}$ & 0.79 & Sum 6 items & $\begin{array}{l}\text { How important do you think these reasons are for being } \\
\text { physically active? 'Health', 'Appearance', 'Weight', 'Feeling fit', } \\
\text { 'Relaxation', 'Stress relief' }\end{array}$ \\
\hline Enjoyment [37] & $\begin{array}{l}\text { 7-point: } 1 \text { (least enjoyable), } \\
7 \text { (most enjoyable) }\end{array}$ & 0.95 & Sum 6 items & $\begin{array}{l}\text { Feelings about physical activity: 'I love it/I hate it', 'I feel } \\
\text { interested/I feel bored', II find it pleasurable/l find it } \\
\text { unpleasurable', 'I find it energising/I find it tiring', 'It makes me } \\
\text { happy//t makes me depressed', 'I feel good physically while } \\
\text { doing it// feel bad physically while doing it' }\end{array}$ \\
\hline Self-efficacy [39] & $\begin{array}{l}\text { 5-point: } 1 \text { (strongly agree), } \\
5 \text { (strongly disagree) }\end{array}$ & 0.82 & Sum 5 items & $\begin{array}{l}\text { I am confident that I could do physical activity even when: 'I am } \\
\text { tired', II am in a bad mood', 'I feel I don't have time', 'I am on } \\
\text { holiday', 'it is raining' }\end{array}$ \\
\hline \multicolumn{5}{|l|}{ Social factors } \\
\hline $\begin{array}{l}\text { Social support from } \\
\text { family/spouse [41] }\end{array}$ & $\begin{array}{l}5 \text {-point: } 1 \text { (never), } \\
5 \text { (very often) }\end{array}$ & 0.76 & Sum 2 items & $\begin{array}{l}\text { During the past year, how often did members of your family: 'Do } \\
\text { physical activity with you?', 'Encourage you to be physically } \\
\text { active?' }\end{array}$ \\
\hline $\begin{array}{l}\text { Social support from } \\
\text { friends/work } \\
\text { colleagues [41] }\end{array}$ & $\begin{array}{l}\text { 5-point: } 1 \text { (never), } \\
5 \text { (very often) }\end{array}$ & 0.69 & Sum 2 items & $\begin{array}{l}\text { During the past year, how often did friends or work colleagues: } \\
\text { 'Do physical activity with you?', 'Encourage you to be physically } \\
\text { active?' }\end{array}$ \\
\hline Childcare & $\begin{array}{l}1 \text { (yes), } 2 \text { (no), } 3 \text { (N/A/I don't } \\
\text { have children) }\end{array}$ & N/A & dichotomise & $\begin{array}{l}\text { If you wanted to do any physical activity without your children, } \\
\text { do you have access to childcare either at a childcare centre, a } \\
\text { partner/family member or a friend? }\end{array}$ \\
\hline \multicolumn{5}{|c|}{ Physical environment factors } \\
\hline $\begin{array}{l}\text { Neighbourhood } \\
\text { walkability [40] }\end{array}$ & $\begin{array}{l}\text { 5-point:1 (strongly agree), } \\
5 \text { (strongly disagree) }\end{array}$ & 0.80 & Sum 7 items & $\begin{array}{l}\text { 'My neighbourhood offers many opportunities to be physically } \\
\text { active', 'Local sports clubs and other facilities in my } \\
\text { neighbourhood offer many opportunities to get exercise', 'It is } \\
\text { pleasant to walk in my neighbourhood', 'The trees in my } \\
\text { neighbourhood provide enough shade', 'In my neighbourhood it } \\
\text { is easy to walk places', 'I often see other people walking in my } \\
\text { neighbourhood', 'I often see other people exercising (e.g., } \\
\text { jogging, bicycling, playing sports) in my neighbourhood' }\end{array}$ \\
\hline $\begin{array}{l}\text { Neighbourhood } \\
\text { aesthetics [40] }\end{array}$ & $\begin{array}{l}\text { 5-point: } 1 \text { (strongly agree), } \\
5 \text { (strongly disagree) }\end{array}$ & 0.76 & Sum 5 items & $\begin{array}{l}\text { There is a lot of rubbish on the street in my neighbourhood', } \\
\text { 'There is a lot of noise in my neighbourhood", In my } \\
\text { neighbourhood the buildings and homes are well-maintained', } \\
\text { 'The buildings and homes in my neighbourhood are interesting', } \\
\text { 'My neighbourhood is attractive' }\end{array}$ \\
\hline Personal safety [40] & $\begin{array}{l}\text { 5-point: } 1 \text { (strongly agree), } \\
5 \text { (strongly disagree) }\end{array}$ & 0.85 & Sum 3 items & $\begin{array}{l}\text { 'I feel safe walking in my neighbourhood, day or night', 'Violence } \\
\text { is not a problem in my neighbourhood', 'My neighbourhood is } \\
\text { safe from crime' }\end{array}$ \\
\hline $\begin{array}{l}\text { Neighbourhood } \\
\text { cohesion [42] }\end{array}$ & $\begin{array}{l}\text { 5-point: } 1 \text { (strongly agree), } \\
5 \text { (strongly disagree) }\end{array}$ & 0.83 & Sum 7 items & $\begin{array}{l}\text { 'People in this neighbourhood can be trusted', 'This is a close- } \\
\text { knit neighbourhood', 'People around here are willing to help } \\
\text { their neighbours', 'People in this neighbourhood generally don't } \\
\text { get along with each other', 'People in this neighbourhood do } \\
\text { not share the same values' }\end{array}$ \\
\hline $\begin{array}{l}\text { Number of } \\
\text { televisions per } \\
\text { household }\end{array}$ & $\begin{array}{l}\text { 5-point: } 0 \text { (None), } \\
4 \text { (four or more) }\end{array}$ & N/A & dichotomise & 'How may televisions do you have in your house?' \\
\hline
\end{tabular}


Table 2 Sociodemographic characteristics of mothers at baseline

\begin{tabular}{|c|c|c|}
\hline Sociodemographic Characteristics & $n$ & Mean $( \pm S D) / \%$ \\
\hline Age (mean years) & 893 & $36.7( \pm 6.2)$ \\
\hline \multicolumn{3}{|l|}{ Education } \\
\hline Low - < Year 12 & 207 & 23 \\
\hline Medium - Year 12/trade/diploma & 429 & 48 \\
\hline High - completed tertiary education & 254 & 29 \\
\hline \multicolumn{3}{|l|}{ Household Income } \\
\hline Low - \$0-699/wk & 612 & 74 \\
\hline Medium - \$700-1499/wk & 146 & 18 \\
\hline High - \$1500+/wk & 14 & 2 \\
\hline Not disclosed & 60 & 7 \\
\hline \multicolumn{3}{|l|}{ Employment Status } \\
\hline Working full-time & 162 & 18 \\
\hline Working part-time & 331 & 38 \\
\hline Not currently working (paid work) & 386 & 44 \\
\hline \multicolumn{3}{|l|}{ Paid Work Status } \\
\hline Not currently working (paid work) & 291 & 33 \\
\hline$<25 \mathrm{~h} / \mathrm{wk}$ & 307 & 35 \\
\hline $25-40 \mathrm{~h} / \mathrm{wk}$ & 222 & 25 \\
\hline$>40 \mathrm{~h}$ hours/wk & 58 & 7 \\
\hline \multicolumn{3}{|l|}{ Marital Status } \\
\hline Married/defacto relationship & 771 & 86 \\
\hline Separated/divorced/widowed & 77 & 9 \\
\hline Never married & 46 & 5 \\
\hline \multicolumn{3}{|l|}{ BMI Status } \\
\hline Not overweight & 454 & 53 \\
\hline Overweight & 227 & 72 \\
\hline Obese & 174 & 20 \\
\hline \multicolumn{3}{|l|}{ Country of Birth } \\
\hline Australia & 829 & 93 \\
\hline Other & 66 & 7 \\
\hline \multicolumn{3}{|l|}{ Age of children living at home } \\
\hline Children aged $0-4$ years & 442 & 49 \\
\hline Children aged $5-12$ years & 453 & 51 \\
\hline
\end{tabular}

Notes; BMI Body mass index
(Table 3). Similarly, mothers reported a median of $1.5 \mathrm{~h}$ per week of transport related physical activity at baseline and $1 \mathrm{~h}$ at follow-up. Mothers reported a median of $24.5 \mathrm{~h}$ per week of screen time activities at baseline and $28 \mathrm{~h}$ at follow-up. Comparisons between baseline behavioural outcomes between participants with and without complete T1 and $\mathrm{T} 2$ data showed no significant differences.

\section{Longitudinal associations with leisure-time physical activity}

Linear regression analysis of the intrapersonal, social and physical environmental factors associated with mother's leisure-time physical activity are shown in Table 4. After adjusting for confounders (model 2), amongst all mothers, all five intrapersonal factors (physical activity enjoyment, outcome expectations, selfefficacy, behavioural intentions and behavioural skills) at baseline were positively associated with leisure-time physical activity at follow-up. A significant interaction $(p<0.05)$ between the child age group and leisure-time physical activity was found for physical activity enjoyment. Further investigation showed that baseline physical activity enjoyment was positively associated with leisure-time physical activity at follow-up among mothers with older children ( $\beta$ 0.27, 95\% CI 0.15,0.39) but not mothers with both younger and older children ( $\beta$ 0.07, 95\% CI -0.08,0.22).

Within the social domain, having social support from friends/work colleagues at baseline was positively associated with leisure-time physical activity at follow-up for all mothers in the adjusted model (Table 4). A significant interaction between the child age group and leisure-time physical activity was found for having support from family/spouse members. Baseline support from family/spouse members was positively associated with leisure-time physical activity at follow-up amongst mothers with older children only $(\beta 0.68,95 \%$ CI 0.27 , $1.10)$ but not mothers with both younger and older children $(\beta-0.20$, 95\% CI -0.60,2.43). No other social factors or child age group interactions were associated with mother's leisure-time physical activity at follow-up.

Neighbourhood cohesion was positively associated with mother's leisure-time physical activity at follow-up, whilst number of televisions was negatively associated

Table 3 Physical activity and sedentary behaviour characteristics of mothers at baseline and follow-up (minutes/week)

\begin{tabular}{lllllll}
\hline $\begin{array}{l}\text { Behavioural } \\
\text { characteristics }\end{array}$ & $\mathrm{T} 1$ & & & $\mathrm{~T} 2$ & \\
\cline { 2 - 3 } & $\mathrm{n}$ & Median $(\mathrm{Q} 25, \mathrm{Q} 75)$ & IQR & & $\mathrm{n}$ & Median (Q25, Q75) \\
\hline Total LTPA & 868 & $100(0,240)$ & 240 & 892 & $120(120,270)$ \\
Total TRPA & 868 & $90(0,180)$ & 180 & 883 & $60(0,180)$ \\
Screen time & 824 & $1470(960,2280)$ & 1320 & 895 & $1680(1080,2520)$ & 180 \\
\hline
\end{tabular}

Notes: LTPA Leisure-time physical activity, TRPA Transport related physical activity, Q25 25th quartile, Q75 75th quartile, IQR Inter quartiles range 
Table 4 Linear regression analysis of the social ecological factors associated with mother's leisure time physical activity

\begin{tabular}{|c|c|c|c|c|}
\hline & \multicolumn{2}{|c|}{ Model $1^{\mathrm{a}}$} & \multicolumn{2}{|c|}{ Model $2^{b}$} \\
\hline & $\beta$ & $(95 \% \mathrm{Cl})$ & $\beta$ & $(95 \% \mathrm{Cl})$ \\
\hline \multicolumn{5}{|l|}{ Intrapersonal } \\
\hline PA enjoyment & 0.20 & $0.11,0.28^{* * *}$ & 0.19 & $0.09,0.28^{* * *}$ \\
\hline Outcome expectations & 0.33 & $0.16,0.50^{* * *}$ & 0.28 & $0.10,0.46^{*}$ \\
\hline Self-efficacy & 0.41 & $0.27,0.55^{* * *}$ & 0.43 & $0.29,0.57^{* * *}$ \\
\hline Behaviour Intentions & 0.76 & $0.37,1.16^{* * *}$ & 0.69 & $0.27,1.11^{*}$ \\
\hline Behaviour skill & 0.74 & $0.43,1.04^{* * *}$ & 0.72 & $0.39,1.06^{* * *}$ \\
\hline \multicolumn{5}{|l|}{ Social } \\
\hline Childcare & 1.00 & $0.02,1.98^{*}$ & 0.44 & $-0.49,1.36$ \\
\hline Social support: family/spouse & 0.23 & $-0.03,0.49$ & 0.27 & $-0.01,0.53$ \\
\hline Social support: friends/work colleagues & 0.54 & $0.28,0.80^{* * *}$ & 0.56 & $0.29,0.84 * * *$ \\
\hline \multicolumn{5}{|l|}{ Environment } \\
\hline Cohesion & 0.35 & $0.13,0.57^{*}$ & 0.34 & $0.09,0.58^{*}$ \\
\hline Safety & 0.06 & $-0.15,0.28$ & 0.04 & $-0.17,0.24$ \\
\hline Aesthetics & 0.25 & $0.01,0.49^{*}$ & 0.22 & $-0.02,0.46$ \\
\hline Walkability & 0.18 & $-0.53,0.31 *$ & 0.14 & $-0.00,0.28$ \\
\hline No. of $\mathrm{TVs}^{\mathrm{c}}$ & -0.29 & $-0.80,0.22$ & -0.69 & $-1.23,-0.16^{*}$ \\
\hline
\end{tabular}

Notes: ${ }^{*} p=<.05,{ }^{*} p=\leq .001,{ }^{* * *} p=.0001 ; \beta$ coefficient, $95 \% \mathrm{Cl}$ Confident intervals

adjusted for baseline variable and clustering by neighbourhoods

badjusted for age, education, number of children, BMl, baseline variable and clustering by neighbourhoods; PA Physical activity, ${ }^{\mathrm{C}}$ Number of television sets per household

with leisure-time physical activity at follow-up among all mothers. No interactions with the age group of the children were detected.

\section{Longitudinal associations with transport-related physical activity}

There were no significant associations between any intrapersonal, social or physical environmental factors at baseline and mother's transport-related physical activity at follow-up (see Table 5). No significant interactions with the child age group were detected.

\section{Longitudinal associations with screen time}

There were no significant associations between any baseline intrapersonal, social or physical environmental factors and mother's screen time at follow-up (Table 6). However, a significant interaction $(p<0.05)$ between child age group and screen time and screen time for neighbourhood cohesion was detected. High levels of neighbourhood cohesion at baseline were longitudinally associated with less screen time at follow-up amongst mothers with both younger and older children $(\beta-0.67$, 95\% CI -1.06,-0.28) but not among mothers with older children only $(\beta 0.10,95 \%$ CI $-0.42,0.62)$.

\section{Discussion}

This study identified several social ecological factors that were longitudinally associated with physical activity and screen time amongst mothers living in socioeconomically disadvantaged neighbourhoods, although longitudinal associations differed according to the domain of physical activity, as well as the age of the mother's children.

Amongst all mothers, all five intrapersonal factors were longitudinally associated with higher levels of leisure-time physical activity. Mothers were more likely to participate in leisure-time physical activity if they enjoyed doing it (particularly amongst mothers with older children only), had outcome expectations, greater self-efficacy, behavioural intentions or behavioural skill. These relationships are consistent with previous cross-sectional research amongst mothers [18, 21, 22], socioeconomically disadvantaged groups $[18,20,45]$ and adults in general [46, 47]. These findings may assist in the development of intervention strategies targeting leisure-time physical activity of mother's from socioeconomically disadvantaged neighbourhoods. Further, findings suggested that having a friend or colleague to exercise with and family support was associated with higher levels of leisure time physical activity, consistent with previous research [21, 48-50]. Therefore, future programs may include mother's yoga classes and women only sport [18] to promote enjoyment and companionship.

This study found that higher levels of neighbourhood cohesion were longitudinally associated with higher levels of mother's leisure-time physical activity, which 
Table 5 Linear regression analysis of the social ecological factors associated with mother's transport related physical activity

\begin{tabular}{|c|c|c|c|c|}
\hline & \multicolumn{2}{|c|}{ Model $1^{a}$} & \multicolumn{2}{|c|}{ Model $2^{b}$} \\
\hline & $\beta$ & $(95 \% \mathrm{Cl})$ & $\beta$ & $(95 \% \mathrm{Cl})$ \\
\hline \multicolumn{5}{|l|}{ Intrapersonal } \\
\hline PA enjoyment & 0.04 & $-0.03,0.11$ & 0.03 & $-0.06,0.10$ \\
\hline Outcome expectations & 0.08 & $-0.08,0.25$ & 0.10 & $-0.08,0.28$ \\
\hline Self-efficacy & 0.08 & $-0.07,0.22$ & 0.06 & $-0.09,0.21$ \\
\hline Behaviour Intentions & 0.13 & $-0.23,0.48$ & 0.18 & $-0.21,0.56$ \\
\hline Behaviour skill & 0.15 & $-0.12,0.41$ & 0.24 & $-0.04,0.52$ \\
\hline \multicolumn{5}{|l|}{ Social } \\
\hline Childcare & -0.17 & $-1.10,0.76$ & -0.17 & $-1.13,0.79$ \\
\hline Social support: family/spouse & 0.12 & $-0.12,0.35$ & 0.12 & $-0.13,0.36$ \\
\hline Social support: friends/work colleagues & 0.10 & $-0.12,0.33$ & 0.10 & $-0.15,0.34$ \\
\hline \multicolumn{5}{|l|}{ Environment } \\
\hline Cohesion & -0.03 & $-0.22,0.17$ & -0.05 & $-0.27,0.17$ \\
\hline Safety & -0.02 & $-0.19,0.16$ & -0.04 & $-0.22,0.13$ \\
\hline Aesthetics & -0.09 & $-0.24,0.67$ & -0.02 & $-0.19,0.15$ \\
\hline Walkability & 0.06 & $-0.08,0.19$ & 0.07 & $-0.08,0.21$ \\
\hline No. of $\mathrm{TVs}^{\mathrm{c}}$ & -0.54 & $-1.18,0.09$ & -0.18 & $-0.81,0.44$ \\
\hline
\end{tabular}

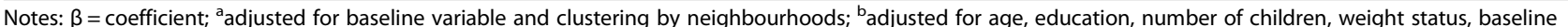
variable and clustering by neighbourhoods; PA Physical activity; ' Number of television sets per household

Table 6 Linear regression analysis of the social ecological factors associated with mother's screen time

\begin{tabular}{|c|c|c|c|c|}
\hline & \multicolumn{2}{|c|}{ Model $1^{a}$} & \multicolumn{2}{|c|}{ Model $2^{b}$} \\
\hline & $\beta$ & $(95 \% \mathrm{Cl})$ & $\beta$ & $(95 \% \mathrm{Cl})$ \\
\hline \multicolumn{5}{|l|}{ Intrapersonal } \\
\hline PA enjoyment & -0.11 & $-0.20,-0.01 *$ & -0.01 & $-0.13,0.11$ \\
\hline Outcome expectations & -0.24 & $-0.46,-0.02^{*}$ & -0.14 & $-0.37,0.08$ \\
\hline Self-efficacy & -0.25 & $-0.44,-0.06^{*}$ & -0.17 & $-0.37,0.26$ \\
\hline Behaviour Intentions & -0.49 & $-0.98,-0.01 *$ & -0.27 & $-0.79,0.26$ \\
\hline Behaviour skill & -0.03 & $-0.44,0.37$ & 0.06 & $-0.37,0.48$ \\
\hline \multicolumn{5}{|l|}{ Social } \\
\hline Childcare & 1.08 & $-0.25,2.41$ & 0.73 & $-0.71,2.17$ \\
\hline Social support: family/spouse & -0.37 & $-0.70,-0.04^{*}$ & -0.26 & $-0.61,0.09$ \\
\hline Social support: friends/work colleagues & 0.01 & $-0.36,0.37$ & 0.08 & $-0.32,0.48$ \\
\hline \multicolumn{5}{|l|}{ Environment } \\
\hline Cohesion & -0.33 & $-0.63,-0.03^{*}$ & -0.29 & $-0.64,0.05$ \\
\hline Safety & -0.15 & $-0.46,0.16$ & -0.15 & $-0.50,0.20$ \\
\hline Aesthetics & -0.15 & $-0.45,0.15$ & -0.13 & $-0.46,0.21$ \\
\hline Walkability & -0.09 & $-0.26,0.08$ & -0.07 & $-0.24,0.11$ \\
\hline No. of $\mathrm{TVs}^{\mathrm{C}}$ & 1.12 & $-0.23,2.02^{*}$ & 0.60 & $-0.42,1.62$ \\
\hline
\end{tabular}

Notes: ${ }^{*} p=<.05 ;{ }^{* *} p=\leq .001 ;{ }^{* * *} p=<.0001 ; \beta=$ coefficient; $^{\text {a }}$ adjusted for baseline variable and clustering by neighbourhoods; ${ }^{\mathrm{b}}$ adjusted for age, education, number of children, weight status, baseline variable and clustering by neighbourhoods; $P A$ Physical activity, $S B$ Sedentary behaviour; ${ }^{C}$ Number of television sets per household 
has previously been shown to be an important factor in physical activity participation amongst women [51, 52] and in particular mothers (children aged 4-10 years living at home) [53]. Further, more televisions in the home were longitudinally associated with lower levels of leisure-time physical activity for mothers at follow-up. To our knowledge, no previous research has investigated the relationship between the number of televisions per household and physical activity amongst mothers or women in general. However, in youths $[54,55]$ (aged 618 years) having more televisions in the house was associated with more time watching television, which then led to lower levels of physical activity. Although further research on the physical environmental factors associated with physical activity amongst mothers is needed, these findings may suggest that future interventions to promote mother's physical activity should consider targeting reducing the number of televisions in the house and enhancing social cohesion in the neighbourhood, such as implementing community-based activities and promoting social engagement. The lack of association for all other environmental variables suggests that individual and social factors may be particularly influential on mother's leisure-time physical activity or other environmental measures (e.g., proximity to local shops/cafes) that were not examined in this project may be associated with leisure-time physical activity.

No significant associations were found between any potential independent variables and transport-related physical activity. Evidence suggests that transport-related physical activity is strongly influenced by the physical and neighbourhood environment [23, 56, 57]. Therefore, mother's participation in this type of physical activity may be more influenced by factors that were not captured in this study, such as proximity to local shops [23], important destinations (e.g., cafes, parks) and services (e.g., doctors, library), access to dedicated cycles and walking lanes and volume of traffic on roads [56, 57]. Transport-related physical activity may also be influenced by the volume of mothers' child-oriented tasks [58-60] such as having to pick up children after school and take them to after-school activities, shopping or other routine tasks. Previous studies have found mothers find it more convenient to drive to do these errands than partake in active transport [56, 61]. Future initiatives may include ensuring 'park and ride/walk' facilities near schools/childcare centres allowing mothers to drive to school, then walk/cycle to work or other errands. An added benefit of this may be in creating safe school environments, which might encourage more children to walk/cycle to school with their mothers.

The current study found higher levels of neighbourhood cohesion were associated with lower levels of screen time amongst mothers with both younger and older children. Mothers within this age group may be accessing local community activities (e.g., playgroup, library story-time and mothers' group) making them feel more secure and connected within their neighbourhood, which then displaces time spent in screen time activities. No previous studies have investigated the link between neighbourhood cohesion and screen time and thus further research is warranted to explore and confirm these findings. No other environmental factors were associated with screen time, and nor were any intrapersonal or social factors. A potential reason may be that the measure of total screen time did not capture time spent in different sedentary behaviours (e.g., television viewing vs computer use vs tablet use) or distinguish between discretionary (e.g., television viewing) and non-discretionary (work-related computer usage) screen time which may have different longitudinal associations. Further, many independent variables measured were physical activity-related (e.g., self-efficacy, behavioural intentions, enjoyment of physical activity, behavioural skill or outcome expectations), rather than targeting screen time specifically.

Limitations of this study should be considered. Firstly, the use of self-report measures may be subject to recall difficulties and response biases. Secondly, selection bias could be present due to a modest response rate (45\%) and drop-out/loss of follow-up between T1 and T2 sample; however, comparisons between mothers with baseline data only and mothers with baseline and T2 data showed no significant difference in behavioural outcomes. Thirdly, although all respondents lived in socioeconomically disadvantaged neighbourhoods, baseline data suggest a proportion of this sample would not be considered socioeconomically disadvantaged based on individual-level socioeconomic characteristics (e.g., 29\% had tertiary education). Therefore, under-sampling of extremely disadvantaged mothers is likely to have occurred and generalisation to all mothers from disadvantaged neighbourhoods may not be possible. Fourth, additional factors not measured in the current analysis may impact physical activity and sedentary behaviours amongst this population group (e.g., weather, distance to local shops, work etc.) and require further investigation. Finally, the multiple models tested could potentially increase the probability of spurious findings. However, we present findings for all pre-specified analyses, provide lower and upper confidence intervals for all estimates, and present exact $p$-values.

A key strength of this study is the large sample size of an understudied and difficult to reach population, which allowed for adjustment of important confounding factors. Further, the longitudinal study design allowed the direction of relationships between to be determined, which builds on the primarily cross-sectional research to date. This study was able to assess intrapersonal, social 
and physical environmental factors that encompass the social ecological model [14], many of which have not been previously examined in the same sample.

\section{Conclusion}

This study identified several factors longitudinally associated with greater leisure-time physical activity (i.e., enjoyment of physical activity and having support from family/ spouse) and less screen time (neighbourhood cohesion) among mothers living in disadvantaged neighbourhoods. Longitudinal associations differed according to the domain of physical activity, as well as the age of the mother's children. Independent variables were primarily associated with leisure-time physical activity and within the intrapersonal domain of the social ecological model suggesting behaviour specific intervention strategies are required. Overall, the findings of this study may help develop targeted interventions and programs aimed at improving mother's physical activity participation and lowering their screen time levels, particularly amongst those living in socioeconomically disadvantaged neighbourhoods.

\section{Acknowledgements}

Not applicable.

\section{Authors' contributions}

KM led data analysis, interpretation of results and writing of the manuscript LA, VC and MT assisted with data analysis, contributed to interpretation of results and drafting of the manuscript. All authors read and approved the final manuscript.

\section{Funding}

This study was funded by a National Health \& Medical Research Council (NHMRC) Strategic Award, ID 374241. The study funder had no role in study design, collection, analysis or interpretation of the data, in writing the report, or in the decision to submit the article for publication. The contents of this article are the responsibility of the authors and do not reflect the views of the NHMRC. VC (ID 100444) is supported by a Heart Foundation Future Leader Fellowship. LA is supported by an Alfred Deakin Postdoctoral Research Fellowship.

\section{Availability of data and materials}

The datasets analysed during the current study are not publicly available due to ethical restrictions (participants have not consented to the use of their data for purposes other than those for which they originally consented). Should a researcher request the data for a particular purpose, an ethically compliant dataset may be made available via the senior author upon approval by the Deakin University Human Research Ethics Committee. Requests can be emailed to: research-ethics@deakin.edu.au

\section{Ethics approval and consent to participate}

Ethics approval to conduct the research was obtained from Deakin University Human Research Ethics Committee (ID-2006-091). All participants provided written consent to participate.

\section{Consent for publication}

Not applicable.

\section{Competing interests}

The authors declare no competing interests.

\section{Author details}

${ }^{1}$ Geelong, Australia, School of Exercise and Nutrition Sciences, Deakin University, Melbourne Burwood Campus, 221 Burwood Hwy, Burwood, VIC 3125, Australia. ${ }^{2}$ Geelong, Australia, Institute for Physical Activity and
Nutrition (IPAN), School of Exercise and Nutrition Sciences, Deakin University, Burwood, Australia. ${ }^{3}$ Menzies Institute for Medical Research, University of Tasmania, Hobart, Australia.

Received: 9 February 2020 Accepted: 20 August 2020

Published online: 28 August 2020

\section{References}

1. World Health Organization. Global Health Risks: Mortality and burden of disease attributable to selected major risks. [Report]: WHO; 2009.

2. Thorp AA, Owen N, Neuhaus M, Dunstan DW. Sedentary behaviors and subsequent health outcomes in adults: a systematic review of longitudinal studies, 1996-2011. Am J Prev Med. 2011;41(2):207-15.

3. Teychenne M, Ball K, Salmon J. Sedentary behavior and depression among adults : a review. Int J Behav Med. 2010;17(4):246-54.

4. Australian Bureau of Statistics. Australian Health Survey: Physical Activity, 2011-12. [Report]. Canberra: Cat. 4364.0.55.004; 2013.

5. Guthold R, Stevens GA, Riley LM, Bull FC. Worldwide trends in insufficient physical activity from 2001 to 2016: a pooled analysis of 358 population-based surveys with 1.9 million participants. Lancet Glob Health. 2018;6(10):e1077-86.

6. World Health Organization. Physical Inactivity: A Global Public Health Problem. WHO: Global Strategy on Diet, Physical Activity \& Health; 2018 [Available from: www.who.int/dietphysicalactivity/factsheet_inactivity/en/].

7. Australian Bureau of Statistics. National Health Survey: First Results, 2014-15. [Report]. Canberra: Cat. 4364.0.55.001; 2015.

8. Bellows-Riecken $\mathrm{KH}$, Rhodes RE. A birth of inactivity? A review of physical activity and parenthood. Prev Med. 2008;46(2):99-110.

9. Cleland V, Ball K, Hume C, Timperio A, King AC, Crawford D. Individual, social and environmental correlates of physical activity among women living in socioeconomically disadvantaged neighbourhoods. Soc Sci Med. 2010;70(12):2011-8.

10. Brown PR, Brown WJ, Miller YD, Hansen V. Perceived constraints and social support for active leisure among mothers with young children. Leis Sci. 2001;23(3):131-44

11. Brown WJ, Trost SG. Life transitions and changing physical activity patterns in young women. Am J Prev Med. 2003;25(2):140-3.

12. Teychenne $M$, Costigan SA, Parker $K$. The association between sedentary behaviour and risk of anxiety: a systematic review. BMC Public Health. 2015;15:513.

13. Koster A, Caserotti P, Patel KV, Matthews CE, Berrigan D, Van Domelen DR, et al. Association of Sedentary Time with mortality independent of moderate to vigorous physical activity. PLoS One. 2012;7(6):e37696.

14. Stokols D. Establishing and maintaining healthy environments: toward a social ecology of health promotion. Am Psychol. 1992;47(1):6-22.

15. Sallis JF, Owen N. Chapter 3, Ecological Models of Health Behavior [Book]. In: Health Behavior: Theory, Research and Practice. Wiley, San Francisco; 2015. p. 42-64. Available from: https://ebookcentral-proquest.com.

16. Mailey EL, Phillips SM, Dlugonski D, Conroy DE. Overcoming barriers to exercise among parents: a social cognitive theory perspective. J Behav Med. 2016;39(4):599-609.

17. Urizar GG Jr, Hurtz SQ, Albright CL, Ahn DK, Atienza AA, King AC. Influence of maternal stress on successful participation in a physical activity intervention: the IMPACT project. Women Health. 2005;42(4):63-82.

18. Fahrenwald NL, Shangreaux P. Physical activity behavior of American Indian mothers. Orthopedic Nurs. 2006;25(1):22-9.

19. Gierc M, Locke S, Jung M, Brawley L. Attempting to be active: self-efficacy and barrier limitation differentiate activity levels of working mothers. J Health Psychol. 2016;21(7):1351-60.

20. Mansfield ED, Ducharme N, Koski KG. Individual, social and environmental factors influencing physical activity levels and behaviours of multiethnic socio-economically disadvantaged urban mothers in Canada: a mixed methods approach. Int J Behav Nutr Phys Act. 2012;9:42.

21. Dlugonski D, Motl RW. Physical activity experiences and beliefs among single mothers: a qualitative study. Res Q Exerc Sport. 2016;87(3):311-7.

22. Dlugonski D, Martin T, Mailey E, Pineda E. Motives and barriers for physical activity among low-income black single mothers. Sex Roles. 2017;77(5/6):379-92.

23. Hamilton K, Cuddihy T, White KM. Perceived environmental correlates and physical activity: what neighborhood aspects really matter for mothers and fathers of Young children? J Community Psychol. 2013;41(6):679-91.

24. Schluter $P$, Oliver M, Paterson J. Perceived barriers and incentives to increased physical activity for Pacific mothers in New Zealand: findings from the Pacific Islands families study. Aust N Z J Public Health. 2011;35(2):151-8. 
25. Clark BK, Peeters GMEE, Gomersall SR, Pavey TG, Brown WJ. Nine year changes in sitting time in young and mid-aged Australian women: findings from the Australian longitudinal study for Women's health. Prev Med. 2014;64:1-7.

26. Li K, Jurkowski JM, Davison KK. Mental health and family functioning as correlates of a sedentary lifestyle among low-income women with Young children. Women Health. 2012;52(6):606-19.

27. Thompson WG, St. Sauver J, Schroeder D. Occupation, sitting, and weight change in a cohort of women employees. J Occup Environ Med. 2018;60(1):44-7.

28. Sugiyama T, Merom D, Van der Ploeg HP, Corpuz G, Bauman A, Owen N Prolonged sitting in cars: prevalence, socio-demographic variations, and trends. Prev Med. 2012;4:315

29. Teychenne M, Hinkley T. Associations between screen-based sedentary behaviour and anxiety symptoms in mothers with Young children. PLoS One. 2016;11:5.

30. von Elm E, Altman DG, Egger M, Pocock SJ, Gøtzsche PC, Vandenbroucke JP. The strengthening the reporting of observational studies in epidemiology (STROBE) statement: guidelines for reporting observational studies. Epidemiology. 2007;18(6):800-4.

31. Ball K, Cleland V, Salmon J, Timperio AF, McNaughton S, Thornton L, et al. Cohort profile : the resilience for eating and activity despite inequality (READI) study. Int J Epidemiol. 2013:42(6):1629-39.

32. Australian Bureau of Statistics. Socio-Economic Indexes for Areas. Census home: ABS; 2018. Available from: www.abs.gov.au/websitedbs/censushome. nsf/home/seifa.

33. Craig $C L$, Marshall AL, Sjöström M, Bauman AE, Booth ML, Ainsworth BE, et al. International physical activity questionnaire: 12-country reliability and validity. Med Sci Sports Exerc. 2003;35(8):1381-95.

34. Ball K, Timperio A, Salmon J, Giles-Corti B, Roberts R, Crawford D. Personal, social and environmental determinants of educational inequalities in walking: a multilevel study. J Epidemiol Community Health. 2007:61(2):108-14.

35. Salmon J, Owen N, Crawford D, Bauman A, Sallis JF. Physical activity and sedentary behavior: a population-based study of barriers, enjoyment, and preference. Health Psychol. 2003;2:178.

36. Giles-Corti B, Donovan RJ. Relative influences of individual, social environmental, and physical environmental correlates of walking. Am J Public Health. 2003:93(9):1583-9.

37. Kendzierski D, DeCarlo KJ. Physical activity enjoyment scale: two validation studies. J Sport Exerc Psychol. 1991;13(1):50-64.

38. Lechner L, Bolman C, Van Dijke M. Factors related to misperception of physical activity in the Netherlands and implications for health promotion programmes. Health Promot Int. 2006;21(2):104-12.

39. Marcus BH, Selby VC, Niaura RS, Rossi JS. Self-efficacy and the stages of exercise behavior change. Res Q Exerc Sport. 1992;63(1):60-6.

40. Mujahid MS, Diez Roux AV, Morenoff JD, Raghunathan T. Assessing the measurement properties of neighborhood scales: from psychometrics to ecometrics. Am J Epidemiol. 2007;165(8):858-67.

41. Sallis JF, Patterson TL, Nader PR, Grossman RM, Pinski RB. The development of scales to measure social support for diet and exercise behaviors. Prev Med. 1987;16(6):825-36.

42. Sampson RJ. Neighborhoods and violent crime: a multilevel study of collective efficacy. Science. 1997;5328:918.

43. Burton N, Brown W, Burton NW, Brown W, Dobson A. Accuracy of body mass index estimated from self-reported height and weight in mid-aged Australian women. Aust N Z J Public Health. 2010;34(6):620-3.

44. World Health Organization. BMI classification. Global Databade on Body Mass Index: World Health Organization; 2006. Available from: http://apps. who.int/bmi/index.jsp?introPage=intro_3.html.

45. Santos I, Ball K, Crawford D, Teixeira PJ. Motivation and barriers for leisuretime physical activity in socioeconomically disadvantaged women. PLoS One. 2016;11:e0147735.

46. Lewis BA, Williams DM, Frayeh A, Marcus BH. Self-efficacy versus perceived enjoyment as predictors of physical activity behaviour. Psychol Health. 2016;31(4):456-69.

47. Rech CR, Reis RS, Hino AAF, Hallal PC. Personal, social and environmental correlates of physical activity in adults from Curitiba. Brazil Prev Med. 2014;58:53-7.

48. Eyler AA, Vest JR. Environmental and policy factors related to physical activity in rural White women. Women Health. 2002;36(2):109-19.

49. Im E-O, Chee W, Lim H-J, Liu Y, Kim HK. Midlife women's attitudes toward physical activity. J Obstet Gyn Neonatal Nurs. 2008;37(2):203-13.

50. Young DR, He X, Harris J, Mabry I. Environmental, policy, and cultural factors related to physical activity in well-educated urban African American women. Women Health. 2002;36(2):29-41.
51. McNeill LH, Kreuter MW, Subramanian SV. Social environment and physical activity: a review of concepts and evidence. Soc Sci Med. 2006;63(4):1011-22.

52. Yip C, Sarma S, Wilk P. The association between social cohesion and physical activity in Canada: a multilevel analysis. SSM - Population Health. 2016;2:718-23.

53. Yuma-Guerrero PJ, Cubbin C, von Sternberg K. Neighborhood social cohesion as a mediator of neighborhood conditions on mothers' engagement in physical activity: results from the geographic research on wellbeing study. Health Educ Behav. 2017:44(6):845-56.

54. Cabanas-Sanchez V, Izquierdo-Gomez R, Garcia-Cervantes L, Castro-Pinero J, Conde-Caveda J, Veiga OL. Environmental correlates of total and domain-specific sedentary behaviour in young people. The UP\&DOWN study; 2019. p. 696-706.

55. Roemmich JN, Epstein LH, Raja S, Yin L. The neighborhood and home environments: disparate relationships with physical activity and sedentary behaviors in youth. Ann Behav Med. 2007:33(1):29-38.

56. Bopp M, Child S, Campbell M. Factors associated with active commuting to work among women. Women Health. 2014;54(3):212.

57. Zenk SN, Horoi I, Jones KK, Finnegan L, Corte C, Riley B, et al. Environmental and personal correlates of physical activity and sedentary behavior in African American women: an ecological momentary assessment study. Women Health. 2017;57(4):446-62.

58. Lyonette C, Crompton R. Sharing the load? Partners' relative earnings and the division of domestic labour. Work Employ Soc. 2014;29(1):23-40.

59. Nyman C, Reinikainen L, Eriksson K. The tension between gender equality and doing gender: Swedish couples' talk about the division of housework. Womens Stud Int Forum. 2018:68:36-46.

60. Walters $P$, Whitehouse G. A limit to reflexivity: the challenge for working women of negotiating sharing of household labor. J Fam Isssues. 2011; 33(8):1117-39.

61. Lee RE, Kim Y, Cubbin C. Residence in unsafe neighborhoods is associated with active transportation among poor women: geographic research on wellbeing (GROW) study. J Transp Health. 2018;9:64-72.

\section{Publisher's Note}

Springer Nature remains neutral with regard to jurisdictional claims in published maps and institutional affiliations.

Ready to submit your research? Choose BMC and benefit from:

- fast, convenient online submission

- thorough peer review by experienced researchers in your field

- rapid publication on acceptance

- support for research data, including large and complex data types

- gold Open Access which fosters wider collaboration and increased citations

- maximum visibility for your research: over $100 \mathrm{M}$ website views per year

At BMC, research is always in progress.

Learn more biomedcentral.com/submissions 